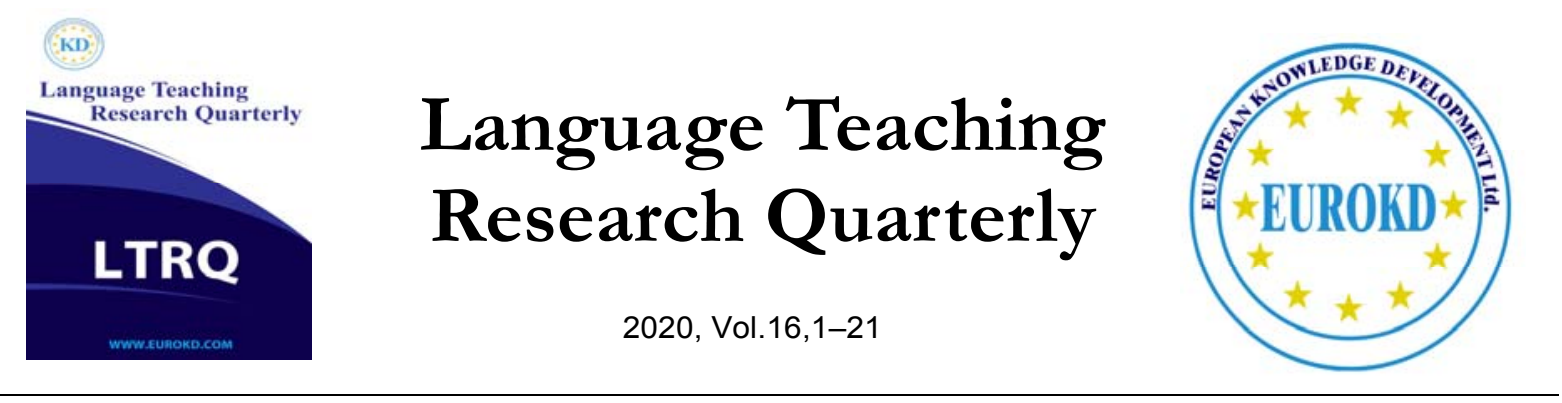

\title{
The Effect of Activity Theory-based Computer-assisted Language Learning on EFL Learners' Writing Achievement
}

\author{
Arezoo Hajimaghsoodi ${ }^{*}$, Parviz Maftoon ${ }^{2}$ \\ ${ }^{1}$ Ph.D. in TEFL, College of Foreign Languages and Literature, Science and Research Branch, Islamic \\ Azad University, Tehran, Iran \\ ${ }^{2}$ Associate Professor, College of Foreign Languages and Literature, Science and Research Branch, \\ Islamic Azad University, Tehran, Iran
}

Received 02 February 2020 Accepted 28 March 2020

\begin{abstract}
Second language writing instruction has been reconceptualized in accordance with the recent shift of paradigm in second language acquisition from a cognitive to a social perspective. Remarkably, this paradigm shift is in line with the introduction of computer technology and sociocultural theory to second language teaching. To explore the combined effect of computer technology and sociocultural theory on second language writing achievement, the researchers utilized an e-learning platform and activity theory to design an activity theorybased computer-assisted language learning framework appropriate for a second language writing course. For this purpose, 67 sophomores majoring in English translation were selected as the participants of this study. A mixed methods embedded research design was employed using various sources of data collection, including a writing pretest and posttest, two questionnaires, and a semi-structured focus group interview. The results indicated that computer-assisted language learning within the activity theory framework had a significant effect on the writing achievement of the students. Besides, the findings revealed that the students had a positive evaluation of the efficacy of the intervention in their writing achievement. This study has some implications for second language educators, researchers, curriculum developers, and courseware designers.
\end{abstract}

Keywords: Activity Theory, Affordance, Computer-Assisted Language Learning, Writing Achievement 


\section{Introduction}

Since the end of the last century, second language acquisition (SLA) research has undergone a paradigm shift from a cognitive orientation to a social orientation (Block, 2003). Interestingly, this paradigm shift in SLA seems to be in alignment with many of the fundamental attributes of computer technology (Irala \& Torres, 2009; Lyster, 2007). Based on this assertion, computerassisted language learning (CALL) is deemed useful for teaching, learning, and researching English as a second/ foreign language (L2). This paradigm shift is also compatible with sociocultural theory in SLA which draws on the work of Vygotsky in viewing learning as the product of mediated activity (Ellis, 2008; Engeström, 1987, 1999; Thorne, 2003). Mediated action is part of activity theory (AT) that has received attention lately. AT "emphasizes the social nature of learning, how individuals' motives affect the nature of the activity they engage in, and the mediating role of artifact in learning" (Ellis, 2008, p. 953).

AT can be employed as a descriptive tool or a framework to conduct diverse research in education (Lantolf \& Appel, 1994; Thorne, 2004), notably in contexts where technology plays a fundamental role as mediation (Blin, 2004). In this perspective, CALL is seen as a mediating tool that stands between subject (usually the student) and object (usually the content to be learned). Thereby, teaching and learning become a unified activity, distributed not only among the community members but also on the artifacts available in the environment (Bannon \& Kaptelinin, 2000). As a result, applications of CALL and AT can be suggested as promising frameworks for teaching language skills.

Among L2 macro-skills, writing has lately gained prime importance not only as a valuable tool for the development of academic language proficiency and a vital skill for academic or occupational success but also as a skill to raise L2 learners' awareness of knowledge gaps (Warschauer, 2010). Thus, writing must be encouraged and fostered during language learners' course of study (Olshtain, 2014). Several theories have been developed over the years to equip teachers with a framework to guide students to enhance their L2 writing skills; however, they had some shortcomings (Gordon, 2008; Hyland, 2003). Atkinson (2003) terms the post-process approach in L2 writing to compensate for the shortcomings of traditional L2 writing teaching approaches. This approach perceives both the writer and the task of writing differently in an expanded and holistic way which involves collaboration among L2 learners and considers both individual and social factors noteworthy in L2 writing.

Therefore, since writing involves a complex phenomenon at various levels, the researchers believe that AT with its six elements of subjects, objects, tools, rules, community, and division of labor, and the way they influence the production of L2 texts can illustrate the L2 writing processes from an alternative perspective, incorporating various social, historical, developmental, and cultural phenomena as they play out in the course of the completion of a writing task. AT can provide a tool for the analysis of how individuals or groups use mediating artifacts to achieve a specific outcome. Thus, in a writing activity, subjects' actions toward objects can be mediated by four interrelated factors--mediating artifacts (e.g., computers, course books, online sources), rules (e.g., class norms and regulations, time limitation, and evaluation 
criteria), community (e.g., teachers, students, friends, family members, classrooms, and academic contexts), and division of labor (e.g., roles to be played and shared in learning activities). Consequently, the combination of AT and CALL can be a useful framework for L2 writing studies since this combination considers both individual and social factors and focuses on collaboration and interaction among learners

Although various studies have shown the possibilities of using computers in accomplishing writing tasks in the classroom (e.g., Fidaoui, Bahous, \& Bacha, 2010; Goldberg, Russell, \& Cook, 2003; Shang, 2007), research on the effect of using CALL via the AT framework on writing skills is relatively new, and it is an area for further research. Besides, students' perception of using AT-based CALL in L2 writing instruction still remains to be explored. Therefore, the present study can be significant in that it can respond to a recent call for foreign language writing research from a sociocultural perspective by using both quantitative and qualitative research methods. The findings of this study may help L2 educators and researchers expand their current understanding of L2 writing and its inter-relatedness with the sociocultural context. Further, this study may help teachers, practitioners, and researchers interested in EFL writing pedagogy to gain insights into the affordances of CALL via AT and to integrate those insights into their activities and instruction to improve students' writing skills.

\section{Review of the Literature}

\section{AT}

AT is based on the theoretical perspective that learning occurs through historically and contextually framed activity in which mediating artifacts have central roles (Mosvold \& Bjuland, 2011). AT is analyzed based on the activity system. Engeström's (1987) activity system (Figure 1) comprised six elements: subject, tools/mediating artifacts, goals including object and outcome, community, division of labor, and rules. Engeström further states that for an activity to be understood in its sociocultural setting, it must be analyzed from the perspective of these six elements.

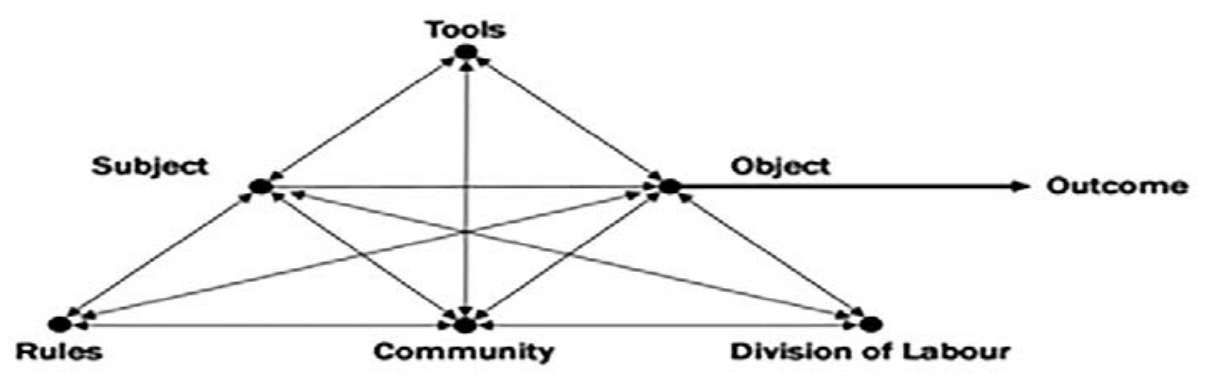

Figure 1. AT system (Adopted from Engeström, 1987, p. 78).

In this system, the subject who uses these artifacts is not an isolated individual but a member of a given community. The members of the community all share a common objective. For the community to exist, a set of rules must be created, and responsibilities must be divided among group members. When a new tool is introduced, it must be mastered by all members of the 
community according to the role assigned to each member. Any action, as well as any task, in the community only makes sense if viewed from a holistic perspective that cannot be separated from its final objective (Engeström, 1999; Kuutti, 1996; Leffa, 2009). Thus, Engeström (1999) contends that learning emerges from the complex result of tool-mediated interactions.

\section{AT and L2 Writing}

The application of AT has recently been developed at a great pace in L2 writing research (Issroff \& Scanlon, 2001). For example, Lei (2008) employed Engeström's AT model and the notion of mediation to identify and explore proficient EFL learners' writing strategies. The study found that EFL learners used four types of mediated strategies. The mediated actions were all oriented toward the learners' goals. The findings showed that the learners' efforts and motivation for the use of strategies were enhanced since they valued their goals and worked proactively to achieve the goals. Furthermore, Rahimi and Noroozisiam (2013) explored the effect of instruction of sociocultural writing strategies and contextual mediations based on Engeström's (1987) AT on the improvement of EFL learners' quality of writing. The results indicated that the instruction significantly improved the writing ability of the students. In another study, Niami (2011) worked on the effect of applications of mediation analysis and AT on writing by reconceptualizing writing revision strategies from a sociocultural perspective. Niami investigated students' revision within the AT framework. She utilized a variety of instruments to obtain data such as a questionnaire, an interview, a process $\log$, etc. Her qualitative results revealed that the students benefited from AT in writing.Abbaspour, Atai, and Maftoon (2020) investigated the impact of scaffolded written corrective feedback within the framework of AT on IranianEFL learners' writing performance in terms of reduction of the learners' writing errors withrespect to the content, vocabulary, mechanics, organization, and grammar. The results indicated that the intervention had a significant impact on students' writing performance.Another study was done by Cheung and Jang (2019)to investigate the impact of writing instruction on students' engagement using the activity theory. The results of qualitative data analysis showed the positive effect of instruction on students' engagement.

\section{CALL and L2 writing}

On the other hand, several studies have demonstrated the usefulness of CALL in L2 writing. As an example, Jones (2006) conducted a study to examine the significance of using a blog for the process writing approach. The study also sought to examine ESL students' perceptions, as well as those of the teacher, regarding the implementation of blogs in the ESL writing class. The findings showed that blogging facilitated the students' critical thinking skills and hada positive effect on the quality of students' writing. In addition, Ghahari and Ameri-Golestan (2014) investigated the impact of blended and classroom teaching methods onIranian EFL learners' writing performance. The results showed that participants receiving blended instruction significantly outperformed the ones receiving only traditional instruction in writing performances. Seyyedrezaie, Ghonsooly, Shahriari, and Fatemi (2016) also investigated the 
effect of writing process in Google Docs environment on Iranian EFL learners' writing performance. The results revealed that Google Docs played an effective role in improving students' writing performance. Moreover, it was revealed that the students generally showed a positive attitude toward the implication of Google Docs as a factor leading to success in their writing performance. Another study was done by Shams-Abadi, Ahmadi, \& Mehrdad (2015) investigating the effect of Edmodo--an e-learning platform--on EFL learners' writing performance. The results indicated that the use of Edmodo significantly improved EFL learners' writing performance.

Despite various studies that have investigated the effect of CALL or AT on L2 writing, scant research is available on the combined effect of CALL and AT on L2 writing. Therefore, the present study is an attempt to hopefully fill the gap in the use of CALL within the AT framework in L2 writing research and to shed new lights on this issue. Thus, the purpose of this study is to examine the effect of AT-based CALL on the writing achievement of Iranian EFL learners. Besides, this study aims to explore the students' overall evaluation of the efficacy of AT-based CALL in writing achievement. To address these goals, the following research questions were formulated:

1. Does AT-based CALL have any statistically significant effect on the writing achievement of Iranian EFL learners?

2. How do Iranian EFL learners evaluate the effect of AT-based CALL on their writing achievement?

\section{Method}

\section{Participants}

The participants of this study were 67 male and female sophomores majoring in English translation taking the Advanced Writing Course that is a part of the requirements of the program to obtain a B.A. degree. The participants have been studying English at the university for two years. Their age range was 19-26. It must be mentioned that as the students were assigned to classes by the university registration office, it was practically impossible for the researcher to disturb the schedules or to rearrange the classes by randomizing the participants. Therefore, the researcher included all the available participants in the first phase of the study; consequently, 75 participants were selected non-randomly based on convenience sampling. After administering the OPT, 67 students whose scores fell between one standard deviation above or below the mean were chosen as participants of this study. Descriptive statistics were conducted after the administration of the test. The mean, standard deviation, and variance of the participants on the OPT are demonstrated in Table 1 below. Table 1 shows that the mean of the scores for the 75 students was 138.12 and the standard deviation was 16.15 . Therefore, those whose scores fell between 121 and 155 were selected as the participants of this study. The participants were at an intermediate level of language proficiency approximately between B1 and B2. According to the CEF scale provided by the Common European Framework of Reference for Languages, scores between 120-150 obtained in the OPT are equivalent to B1 and B2 (Allan, 2004). In each class, 
the same instructor, the same method of instruction, and the same instructional materials and contents were used.

Table 1.

Descriptive Statistics of the OPT

Descriptive Statistics

\begin{tabular}{llllllll}
\hline \multirow{2}{*}{ OPT } & $\mathrm{N}$ & Min. & Max. & Mean statistic & Std. Error & Std. statistic & Variance \\
\cline { 2 - 7 } & 75 & 70 & 179 & 138.12 & 1.86 & 16.15 & 260 \\
\hline
\end{tabular}

\section{Instruments}

In order to pursue this study, the researchers administered two writing tasks, one (pretest) before and the other (posttest) after the treatment. Both tasks were parallel as the developmental pattern of both was cause-and-effect. The pretest topic was The Effects a Good/Bad Teacher Can Have on Someone's Life, and the posttest topic was The Effectsa Good/Bad Friend Can Have on Someone's Life. A writing scale developed by Jacobs, Zinkgraf, Wormuth, Hartfiel, and Hughey (1981, p. 30) was also employed to evaluate the writing samples. In Jacobs et al.'s scale, scripts are rated on five aspects of writing: content, organization, vocabulary, language use, and mechanics. The scale is based on a 100-point scheme, 30 points to the content, 20 points to the organization, 20 points to vocabulary use, 25 points to language use, and 5 points to mechanics. Moreover, an online course was created and designed by the researchers on Eliademy, an elearning platform that allows educators to create, share, and manage online courses. In addition, a closed-ended questionnaire (Appendix A) was used at the end of the course to investigate the participants' overall evaluation of the course. The questionnaire was developed by the researchers based on the relevant literature and then validated in the piloting phase of the study. The reliability of the questionnaire was calculated by Cronbach's Alpha formula and it was 88.An open-ended questionnaire (Appendix B) was also designed to explore the participants' evaluation of the course and to compensate for the shortcomings of pre-set responses in the closed-ended questionnaire. Finally, a semi-structured focus group post-interview was conducted to extract more information and cross-validate the data obtained in the open-ended questionnaire addressing the participants' evaluation of AT-based CALL. The interview was conducted with 20 students and took about 90 minutes.

\section{Procedure}

Data were collected in regular class time over a period of 16 sessions; each session took one hour and 30 minutes. The first and last sessions were allotted to the pretest and posttest. The other sessions were devoted to writing instruction via the AT-based CALL framework. In what follows, the whole procedure is described.

Before the treatment started, an online Advanced Writing course was designed and piloted on Eliademy based on the six elements of AT (subjects, objects, mediating artifacts, rules, community, and division of labor) suitable for EFL writing classrooms. The framework of this 
study is depicted in Figure 2.

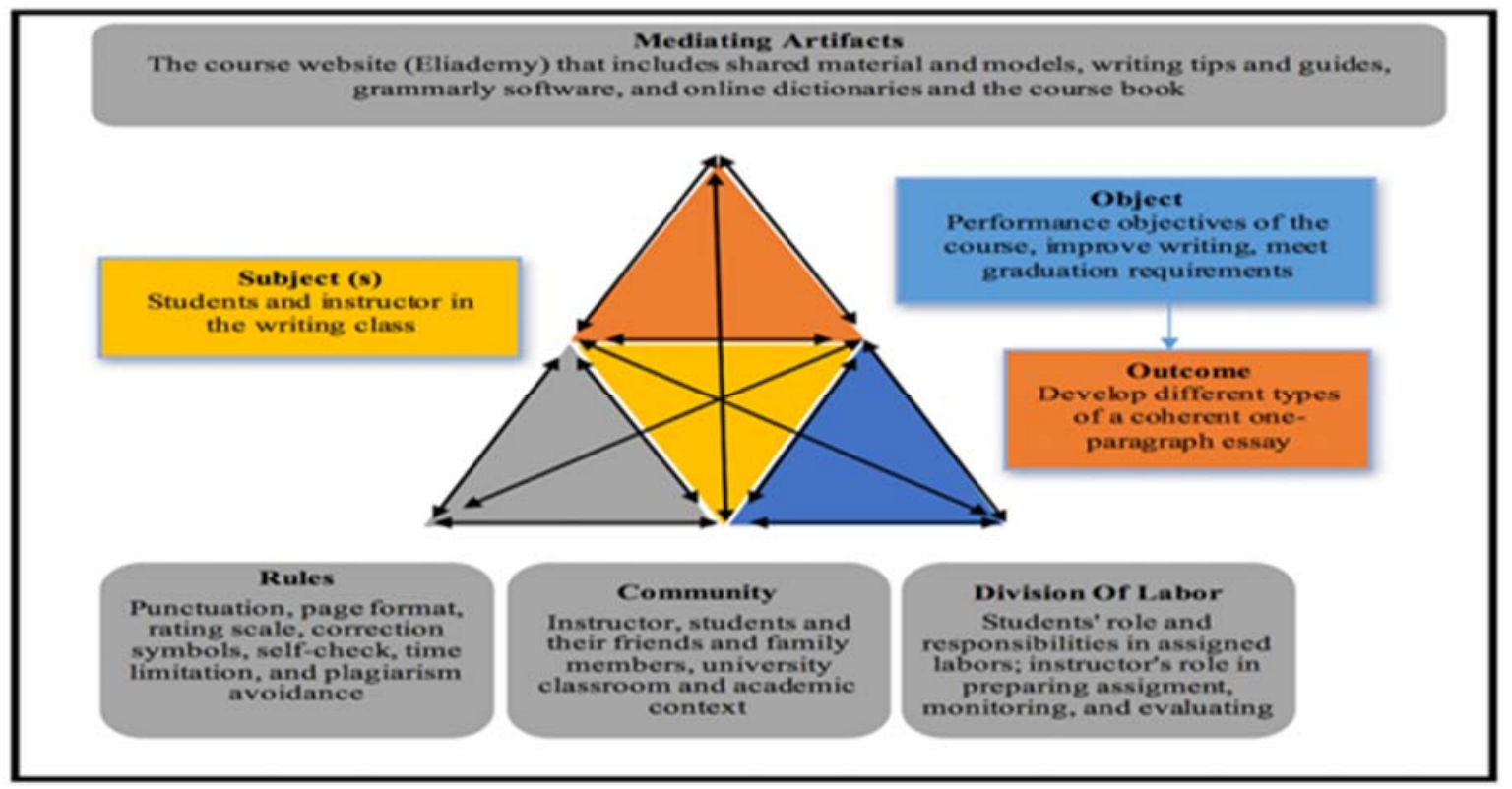

Figure 2. Designed AT-based CALL framework of the study (Adopted from Author \& Author, 2018, p.x)

Then in the first class session, the writing pretest was run. All the participants were asked to write a paragraph (100-150 words) on the topic assigned by the instructor, the first author of the present paper. After that, during the next two sessions, the instructor introduced the course and the e-learning platform. The students were notified of the course requirements, its objectives, and the procedure of the class. Besides, they were thoroughly informed how to use the platform. Then the students were invited to the online course via an invitation email. The step-by-step instructions on how to accept the invitation, sign up, and then log in were clearly supported.

Afterwards, the fourth and fifth sessions of the class focused on instructing the basic components of a paragraph--topic sentence, supporting sentences, concluding sentence--as well as paragraph unity and coherence. From the sixth session on, different developmental patterns of a paragraph (enumeration, process, chronology, cause and effect, comparison and contrast, and definition) were taught based on the course book Paragraph Development by Arnaudet and Barrett (1990). On the whole, it took 10 sessions to teach all the patterns. The instruction was based on a five-step process for building writing skills: prewriting, organizing, writing the first draft, revising and editing, and writing a new draft. In order to teach each developmental pattern, first, the purpose and basics of each pattern were explained. Next, a paragraph model was provided, analyzed, and graphically explained. Finally, some exercises were done in the class, and further explanations were provided, when needed. After teaching a developmental pattern of a paragraph, the instructor posted two topics as weekly assignments in the discussion section of the platform. The students had to choose one of those topics and compose a paragraph as their weekly assignment. In addition to the topics, some other files such as Writing Tips concerning that particular developmental pattern, Objectives of that developmental pattern, the writer's Self- 
Check, and two or more Writing Models were posted. Besides, another file, Assigned Labors, was attached by the instructor in order to divide labors amongst the participants. In this regard, some students were assigned to provide ideas related to the topic, some to find related transitional signals and examples, some to provide topic-related vocabulary items and phrases, and still some others to find model paragraphs. These roles were assigned randomly based on a step-by-step approach to a writing assignment that focuses on integrating writing skills to guide students to develop well-organized paragraphs through the steps of the prewriting process recommended by some scholars (see, for example, Meyers, 2006; Oshima \& Hogue, 2014; Ruetten, 2012; Zemach \& Rumisek, 2005). The course participants were required to post and share their assigned tasks in the discussion section of the e-learning platform under the instructor's posted assignments, and the instructor continuously checked, monitored, and evaluated whether the participants accomplished their assigned labors successfully or not. Each participant's role was changed every week to let them adopt various roles at different times and to avoid rigid group structures. It is worth mentioning that the participants were also encouraged to share any other materials or tools they found interesting and useful than those assigned by the instructor. All the participants were required to be vigorously engaged in the activities and accomplish their assigned roles before they write a paragraph. In doing so, the participants could get help from the instructor, the classmates' shared materials, other members of the community, and the elements of the designed platform such as Connecting Words and Transition Signals, Grammarly software, General Writing Tips, Pre-Writing Techniques, Rating Scale, etc. Figure 3 illustrates samples of weekly assignments and students' engagement in the assignments on the platform.

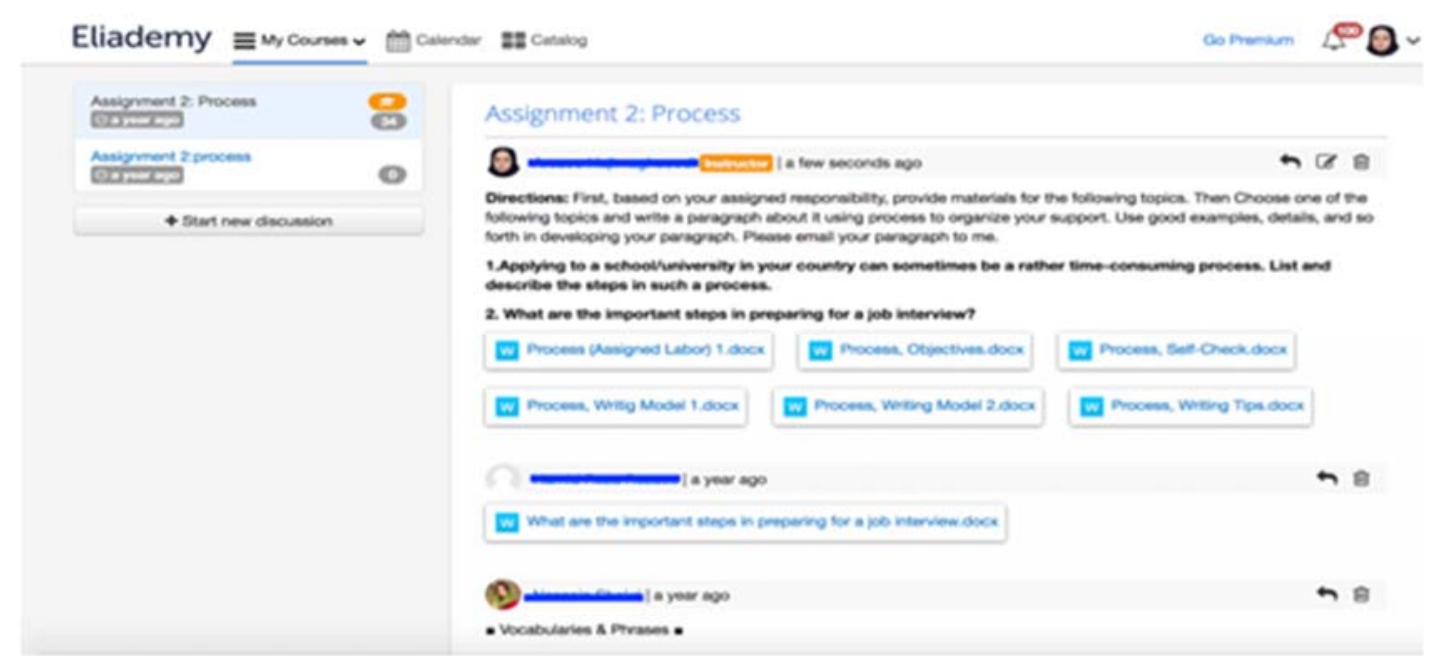




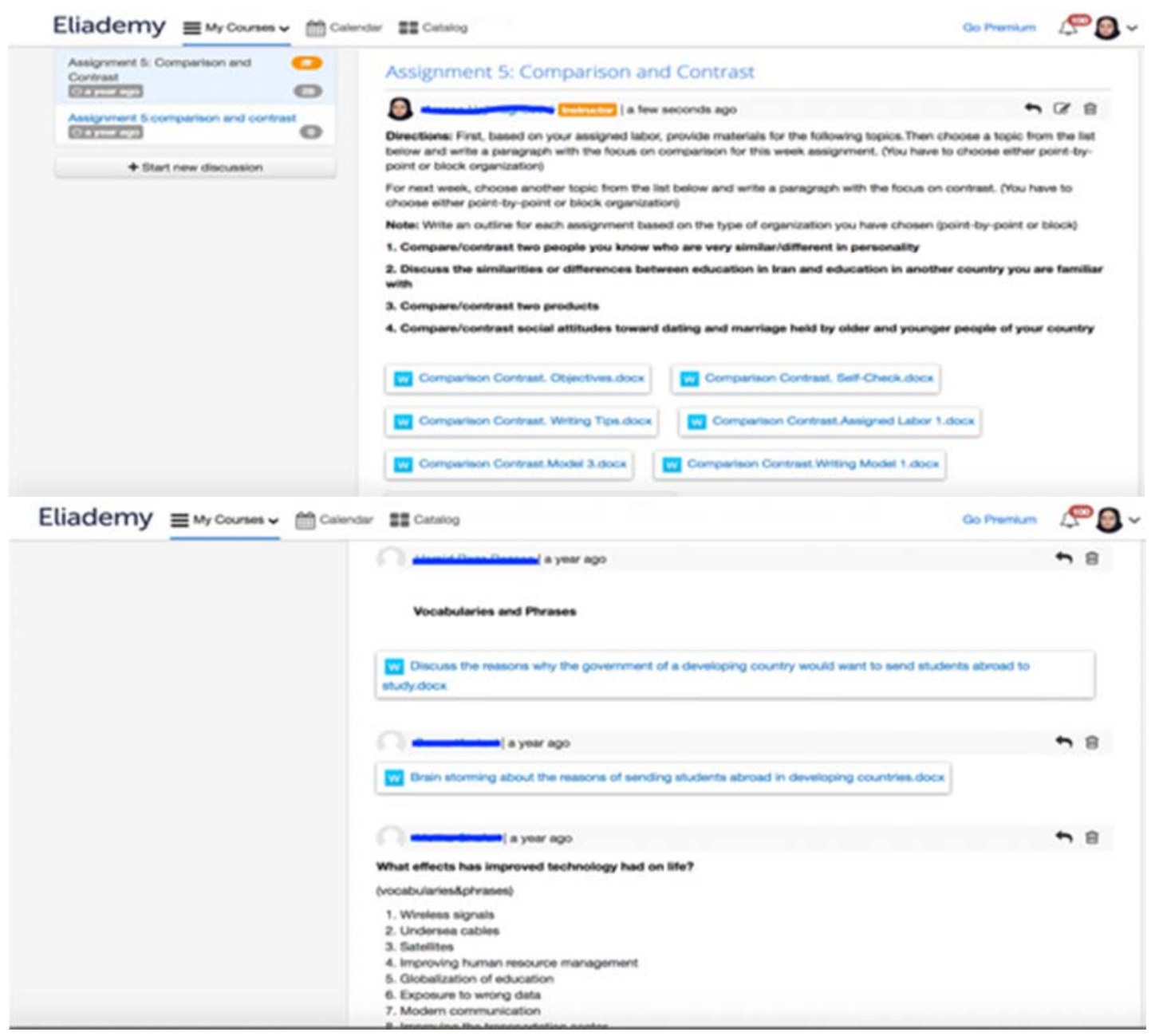

Figure 3. Screenshot of samples of weekly assignment and students' engagement on Eliademy

After the participants composed their first drafts, they had to check the drafts against the rules and conventions (Page Format, Punctuation Rules, and Self-Check) available on the platform and then email the paragraphs and the completed self-checks to the instructor. The selfcheck worksheets included yes/no questions about the required aspects that the instructor expected the participants to take into account while writing each developmental pattern of a paragraph. The worksheets comprised proofreading to check for and correct errors in format, content and organization, mechanics, grammar, and sentence structure in order to assist the participants in figuring out their strengths and weaknesses in rhetorical skills, as well as their errors. The self-check worksheets were adapted from Oshima and Hogue (2014). The efficacy of the self-check worksheets on the participants' writing progress was investigated through the participants' comments and responses to the questionnaires and the interview.

Afterwards, the instructor evaluated and scored the students' weekly assignments based on Jacobs et al.'s (1981) writing scale, provided written comments and unfocused feedback, and then posted some scored samples on the platform to be visible for all. In fact, this formative 
assessment was carried out in order to monitor and measure the participants' progress during the writing, rewriting, and the cooperative learning process and to diagnose the students' strengths and weaknesses in writing. Finally, the participants were required to check the samples and edit their paragraphs based on the comments provided. They had to email the final drafts of the assigned paragraphs to the instructor at the end of the semester.

After the treatment, the students were given the AT-based CALL closed- and open-ended questionnaires, and the instructor scheduled an interview with 20 students. At the end of the course, on the exam session, the writing posttest was administered to the students. They had to write a paragraph (100-150 words) on the posttest topic assigned by the instructor. The purpose of the posttest was to compare the participants' mean score on the pretest with that of the posttest and to determine whether AT-based CALL had any significant effect on the participants' writing achievement. The writing samples in both pretest and posttest were scored analytically by two raters using the rating scale proposed by Jacobs et al. (1981).

\section{Research Design}

Both quantitative and qualitative research methods were used simultaneously in this study. In fact, the qualitative data were collected and analyzed to support the quantitative data. Therefore, this study was a mixed methods embedded design that is built on the premise that a single set of data is not satisfactory. This design could compensate for the shortcomings of the quantitative data collection method which was pre-experimental research with pretest/posttest design. In fact, in this study, various research methods of obtaining data were used to triangulate the findings and consequently enhance the generalizability of the research findings and reduce the practice effect (Mackey \& Gass, 2005).

\section{Results}

In order to answer the research questions, first, the normality of the data was checked. Then the inter-rater and intra-rater reliabilities of the writing tests were calculated. Finally, a pairedsamples t-test was run to compare the mean scores of the participants.

\section{Testing the normality of the data}

The normality of the data on the writing pretest and posttest was checked by computing the ratios of the skewness and kurtosis over their standard errors. Since the absolute values of the ratios were within the acceptable range of +1.96 and -1.96 (Table 2), it can be concluded that the present data met the normality assumption.

Table 2.

Descriptive Statistics of the Pretest and Posttest of Writing

\begin{tabular}{lllllllll}
\hline & $\mathrm{N}$ & \multicolumn{3}{c}{ Skewness } & \multicolumn{5}{c}{ Kurtosis } \\
\cline { 2 - 9 } & Statistic & Statistic & Std. Error & Ratio & Statistic & Std. Error & Ratio \\
\cline { 2 - 9 } Pretest of Writing & 67 & .117 & .293 & 0.40 & -.863 & .578 & -1.49 \\
Posttest of Writing & 67 & .440 & .293 & 1.50 & .193 & .578 & 0.33 \\
\hline
\end{tabular}


Inter-rater and intra-rater reliability of the writing tests

A series of intraclass correlation coefficient was conducted to calculate the inter-rater and intrarater reliability of the writing pretest and posttest scores. All the inter-rater and intra-rater reliability indices enjoyed statistical significance. The highest index was .98 , and the lowest one was estimated .72 .

$R Q_{1}$ : Does AT-based CALL have any statistically significant effect on the writing achievement of Iranian EFL learners?

A paired-samples t-test was run to compare the participants' mean scores on the pretest and posttest of writing in order to probe the first major research question. As Table 3 shows, the participants had a higher mean score on the posttest of writing $(\mathrm{M}=81.90, \mathrm{SD}=7.74)$ than that of the pretest $(\mathrm{M}=63.60, \mathrm{SD}=12.48)$.

Table 3.

Descriptive Statistics of the Pretest and Posttest of Writing

\begin{tabular}{|c|c|c|c|c|c|}
\hline & & Mean & $\mathrm{N}$ & Std. Deviation & Std. Error Mean \\
\hline \multirow{2}{*}{ Writing } & Posttest & 81.903 & 67 & 7.7456 & .9463 \\
\hline & Pretest & 63.604 & 67 & 12.4817 & 1.5249 \\
\hline
\end{tabular}

The results of the paired-samples t-test $\mathrm{t}(66)=15.17, \mathrm{p}<.05$ (two-tailed) (Table 4) indicate that the EFL learners performed significantly better on the writing posttest. The mean score increase in the posttest was 18.29 with a $95 \%$ confidence interval ranging from 15.89 to 20.7. Besides, the eta squared statistic was calculated to determine the strength of the intervention's effect. Eta squared statistic was estimated .77 which implies a large effect size due to Cohen's standard (Pallant, 2013). Eta squared statistic of 0.77 indicates that the intervention accounted for $77 \%$ of the variability in the writing scores of the participants; consequently, it can be claimed that the positive results are not due to the practice effect which is usually a matter of concern in long-term research. Therefore, the answer to this research question is positive.

Table 4.

Paired-samples T-test of the Pretest and Posttest of Writing

\begin{tabular}{|c|c|c|c|c|c|c|c|}
\hline \multicolumn{5}{|c|}{ Paired Differences } & \multirow{3}{*}{$\mathrm{t}$} & \multirow{3}{*}{ df } & \multirow{3}{*}{$\begin{array}{l}\text { Sig. } \\
\text { (2-tailed) }\end{array}$} \\
\hline \multirow{2}{*}{ Mean } & \multirow{2}{*}{ Std. Deviation } & \multirow{2}{*}{ Std. Error Mean } & \multicolumn{2}{|c|}{$95 \%$ Confidence Interval of the Difference } & & & \\
\hline & & & Lower & Upper & & & \\
\hline 18.2985 & 9.8735 & 1.2062 & 15.8902 & 20.7068 & 15.170 & 66 & .000 \\
\hline
\end{tabular}

In addition, the results of the instructor's formative assessment of the participants' weekly assignments confirmed the participants' progress in writing during the intervention. 
RQ2: How do Iranian EFL learners evaluate the effect of AT-based CALL on their writing achievement?

The participants' overall evaluation of the efficacy of AT-based CALL in writing achievement was collected via the closed- and open-ended questionnaires and the semi-structured focus group interview.

Based on the questionnaire with 38 five-point Likert items, the scores of the participants could range from 38 (the lowest) to 190 (the highest). The results of descriptive statistics of the participants' self-report on the AT-based CALL closed-ended questionnaire (Table 5) demonstrate that Iranian EFL learners had a positive evaluation $(M=124.43, S D=17.82)$ of the efficacy of AT-based CALL in writing achievement. Besides, the results of the summary item statistics $(\mathrm{M}=3.27, \mathrm{SD}=1.07)$ indicate that the participants' responses to the questionnaire fell into the upper intermediate category, which again demonstrate a positive evaluation of the instruction (Table 6). It must be mentioned that as the questionnaire was a five-point Likert items, the highest mean in summary item statistics could be 5 and the lowest one could be 1 .

Table 5.

Descriptive Statistics of the Participants' Responses to AT-Based CALL Questionnaire

\begin{tabular}{lllll}
\hline & Mean & Variance & Std. Deviation & N of Items \\
\hline AT-basedCALL Questionnaire & 124.4328 & 317.734 & 17.8251 & 38 \\
\hline
\end{tabular}

Table 6.

Summary Item Statistics of the Participants' Responses to AT-Based CALL Questionnaire

\begin{tabular}{lllllllll} 
& Mean & Std. Deviation & Min. & Max. & Rang & Max./Min & Variance & N of Items \\
\hline Item Means & 3.275 & 1.07 & 1.269 & 4.388 & 3.119 & 3.459 & .679 & 38 \\
\hline
\end{tabular}

These findings were also supported by the participants' responses to the open-ended questionnaire and semi-structured interview. The participants' responses were read carefully several times, transcribed verbatim, coded, and then grouped into themes that recurred frequently. The main themes obtained can be categorized into three groups: (1) outcomes, (2) affordances, and (3) constraints.

Outcomes. The first main theme extracted from the students' responses was based on the outcomes of the instruction. This theme was further categorized into three sub-themes: (1) improvement, (2) satisfaction, and (3) attitude change.

All the students reported improvement in their writing skills at the end of this course. They also noted improvement in their five aspects of writing, that is, content, organization, use of vocabulary items, language use, and use of mechanics. Regarding these aspects, although they expressed different ideas, most of them favored improvement. Almost all the students $(95.52 \%)$ 
acknowledged improvement in their writing organization. After organization, the use of mechanics $(89.55 \%)$ got the highest rank. However, it must be mentioned that some of the students $(37.31 \%)$ claimed that their spelling did not improve due to the automatic spelling check in Microsoft Word Offices. The third aspect of writing that many students $(88.05 \%)$ found improvement was content. Regarding the use of vocabulary items, about $(85.07 \%)$ of the students reported improvement. Finally, improvement in language use was considered by $71.64 \%$ of the students. Besides, most of the students (88.05\%) claimed that they were satisfied with the progress they had in their writing at the end of the semester. Some of the participants (41.79\%) also noted that their attitude toward writing had changed. Some of their comments are as follows: "It really improved my writing, and writing a paragraph became easy for me." "At first, my writing was very poor but it has remarkably improved during this course." "I'm satisfied because my first paragraph was completely different in comparison with my final paragraph." "I did not use to like writing because of the traditional writing methods, but now I like it." "In this course, I figured out how much I love writing."

Affordances. The second main theme derived from the students' responses was related to their perceived affordances of the AT-based CALL instruction. This theme was also divided into five sub-themes: (1) interaction and cooperation, (2) access, (3) computer skills, (4) novelty, and (5) motivating atmosphere.

Most of the students $(80.59 \%)$ acknowledged that employing AT-based CALL promoted interaction and cooperation among learners. They liked the idea of division of labors and stated that the cooperative learning process influenced their writing positively. Besides, about $58 \%$ of the students highly commended the accessibility of the platform and the availability of all the required materials and sources. Many of the participants (67\%) acknowledged the effectiveness of the self-checks in improving their writing. Moreover, a large number of students (79\%) stated that their computer skills had improved. Furthermore, almost all the students (91.04\%) perceived the novelty of the procedure followed in this course as an affordance. Finally, the stress-free and motivating atmosphere of the course was noted by a majority $(83.58 \%)$ of the students. Some examples of the students' comments are as follows: "The main strength was prompting students to cooperate." "The most effective aspect was the interaction between the instructor and the students." "The main strength of the website was that it was easy to access and use." "I think the website was very good because we could easily access previous assignments and models." "My computer skills have improved during this course." "It helped me to learn how to work with laptops, practice typing, and search the Net. Totally, it opened a new way of working with computers." "I liked this course because I'm tired of the repetitive ways of teaching using only books and papers. It is different from other courses." "I liked the course because of the new ways of teaching like using the website, assigned labors, etc." "The class procedure was friendly and I really enjoyed the positive atmosphere of the website and the class."

Constraints. The third main theme extracted from the students' responses was the constraints of the instruction. Constraints were categorized into two sub-themes: (1) the Internet speed and (2) time commitment. 
A few students $(25.37 \%)$ reported the speed of the Internet connection as one of the constraints that sometimes prevented them from accessing the platform. Moreover, about $42 \%$ of the students stated that the AT-based CALL instruction was time-consuming and difficult to follow. These constraints are illustrated in the following excerpts: "We could not sometimes open or access the website due to the Internet speed." "I really improved, but it took a lot of time to do my assignments." "It was difficult to send emails and share weekly assignments in due time every week." "Some students didn't know how to send an email or even work with laptops, so it was difficult for them to work with the course website."

\section{Discussion}

This study aimed to investigate the effect of using AT-based CALL on the writing achievement of Iranian EFL learners. It was assumed that teaching writing by using CALL within the AT framework would enhance students' writing performance and provide affordances for them. The findings of this study revealed that AT-based CALL significantly enhanced Iranian EFL learners' writing skills. All the students performed substantially better on the writing posttest than the writing pretest after receiving the AT-based CALL instruction. These findings show that the students made noticeable progress in their L2 writing as a result of using different mediating elements of this combined instruction to transform their writing activities by providing various tools and resources. These results can be justified and are in accordance with what the literature review shows regarding the nature and influence of CALL and sociocultural theory which AT is part of it on writing achievement (e.g., Jafarian, Soori, \& Kafipour, 2012; Seyyedrezaie, Ghonsooly, Shahriari, \& Fatemi, 2016; Shams-Abadi et al., 2015; Shang, 2007; Villamil \& de Guerrero, 1996).

The effectiveness of AT-based CALL instruction can be attributed to its sociocultural nature in viewing learners as members of a group practicing in social contexts. This view illustrates how learners can assist each other and at the same time benefit from other sources or artifacts and members of the community to achieve their goals through a consistent reciprocal relationship in the learning community. In fact, CALL within the AT framework can mediate students' writing activities in several ways by allowing students to pursue different motives simultaneously. CALL as a means of instruction within the AT framework supports a variety of learning activities and facilitates collaboration, cooperation, and interaction both within and beyond the classroom. Thus, the effectiveness of the instruction can be attributed to the collaborative and negotiated nature of AT-based CALL, the learners were highly involved in the writing process. This process afforded learners with significant assistance to progress from the other-regulated stage to the self-regulated stage. Such transition empowered the learners to excel in their writing performance. Besides, implementing online educational tools such as CALL in EFL contexts can reduce students' stress, build up a positive attitude toward L2 writing, and increase their motivation. Word processor utilized in this study, for instance, provides composing environments that facilitate writing by making drafting, revising, and editing much easier and quicker, thus offering opportunities for learners to engage with the creative process of 
construction. These features seem to be in agreement with student-centered learning which addresses the learning needs and interests of students in the $21^{\text {st }}$ century by encouraging students to actively engage in their own learning. Hence, AT-based CALL can provide an alternative approach to boost L2 writing skills.

Moreover, the results of the questionnaires and interview pertaining to the students' evaluation of the effectiveness of AT-based CALL imply the beneficial application and affordances of the instruction in L2 writing. The students reported that AT-based CALL in L2 writing led to improvement, satisfaction, and attitude change. They also found AT-based CALL accessible, new, motivating, and effective in encouraging interaction and cooperation and developing computer skills. However, it is noteworthy to mention that this combined instruction may suggest different affordances to different learners or even to the same learners at different times or contexts. These findings are not surprising because similar results were found in other studies investigating students' evaluation of the effectiveness of AT and CALL in L2 writing skill (e.g., Brine \& Franken, 2006; Che Wan Ibrahim, 2013; Naimeh, 2017; Portnov-Neeman \& Barak, 2013; Seyyedrezaie et al., 2016; Shang, 2007; Warschauer, 1996). In addition, similar affordances were found in some previous studies addressing either issue, AT or CALL (e.g.,Seyyedrezaie et al., 2016; Shams-Abadi et al., 2015).

The participants' positive perception can be attributed to the novelty of the treatment in incorporating technology into L2 writing instruction and encouraging social learning among the students which are in line with the needs of students in this century. Another possible reason why the participants had almost a positive perception toward the instruction was that they had access to a computer and the Internet and had adequate computer skills to accomplish their assignments and benefit from the e-learning platform.

On the other hand, the results of the students' evaluation of the instruction indicate that the Internet speed and time commitment were considered as the constraints of AT-based CALL. The same problems were mentioned by the students in some other studies (e.g., Brine \& Franken, 2006; Chen Hsieh, Wu, \& Marek, 2016; Seyyedrezaie et al., 2016). These constraints are usually among the most prominent concerns of instructors who prefer to implement online educational tools in some EFL contexts. Time commitment is perceived as a constraint because there are always some students who lack adequate basic computer skills. Therefore, it takes more time to accomplish an assignment or a task on a computer than its counterpart on a paper. To help address this concern, the instructor provided consistent training for the students to learn basic computer skills and tried to familiarize them with the use and effectiveness of incorporating computer technology into teaching and learning.

\section{Conclusion}

Drawing on sociocultural theory and CALL, this study explored the effect of AT-based CALL on the writing achievement of Iranian EFL learners. With the multiple sources of data collected, the results depicted a positive picture of AT-based CALL in L2 writing classes at the tertiary level in Iran. Thus, it is concluded that the multidimensional integration of theories can suggest a 
useful framework for L2 writing instruction and future studies in the related field. Therefore, teachers should know how to use computer skills and integrate those skills into language classrooms to boost students' interest and motivation. Furthermore, it is suggested that conventional teaching methods should be superseded by methods that promote a constructivist learning environment in which students interact with tools, community, division of labor, and rules and play an active part in forming and shaping their learning to arrive at better outcomes.

However, it must be pointed out that in integrating CALL and AT, what is of prime importance is the role of the instructor. That is why Hanson-Smith and Rilling (as cited in Villalobos, 2014) claim that technology in education begins and ends with teachers. HansonSmith and Rilling mean that if language teachers are not interested in technology, students will not be interested in experiencing learning within that framework.

The results of this study maintain pedagogical implications for EFL teachers and syllabus designers in that they become acquainted with the worthwhile effects that the combination of AT and CALL can have on improving writing skills and fostering interest, motivation, and cooperation amongst students. Another pedagogical implication of the study to mention is that this study provides foreign language educators, researchers, and curriculum planners with new insights into the potential affordances and constraints of AT-based CALL in L2 writing classes in order to enable them to integrate those insights into their activities and instruction to develop students' writing skills. In addition, the findings of the present study can be of help to language courseware designers, e-learning platform developers, and course administrators to build up their practices and decisions, especially in providing and implementing CALL and AT in L2 writing instruction.

The results of this research, though limited in scope, advocate that implementing AT-based CALL in L2 writing instruction is beneficial for EFL learners, thus paving the way for further research in this area. Consequently, attempts should be made to integrate and exploit AT and CALL in writing instruction. Besides, this AT-based CALL framework can be useful in teaching other language skills although the tools and objectives would be different.

\section{References}

Abbaspour, E., Atai, M. R., \& Maftoon, P. (2020). The Effect of scaffolded written corrective feedback on Iranian EFL Learners' writing quality: An activity theory perspective. International Journal of Foreign Language Teaching and Research, 8 (30), 177-196. Retrieved from http://jfl.iaun.ac.ir/article_671067.html

Arnaudet, M. L., \& Barrett, M. E. (1990). Paragraph development ( $2^{\text {nd }}$ ed. $)$. New Jersey: Prentice Hall Regents.

Atkinson, D. (2003). L2 writing in the post-process era: Introduction. Journal of Second Language Writing, 12 (1), 3-15. doi:10.1016/s1060-3743(02)00123-6

Bannon, L., \& Kaptelinin, V. (2000). From human-computer interaction to computer mediated activity. In C. Stephanidis (Ed.), User interfaces for all: Concepts, methods, and tools (pp. 183-202). Mahwah, NJ: Lawrence Erlbaum.

Blin, F. (2004). CALL and the development of learner autonomy: Towards an activity theoretical perspective. ReCALL, 16(2), 377-395.doi:10.1017/s0958344004000928 
Block, D. (2003). The social turn in second language acquisition. Washington, DC: Georgetown University Press.

Brine, J., \& Franken, M. (2006). Students' perceptions of a selected aspect of a computer mediated academic writing program: An activity theory analysis. Australasian Journal of Educational Technology, 22(1), 21-38. Retrieved from http://ajet.org.au/index.php/AJET/article/view/1305/677

Che Wan Ibrahim, C. W. I. R. (2013). Perceived affordances and learning strategies of Malaysian university students in web 2.0 based informal learning of English as a second language: Amixed methods study (Doctoraldissertation,LatrobeUniversity).Retrievedfromhttp://arrow.latrobe.edu.au:8080/vital/access/manager/Re positorylatrob:35053

Chen Hsieh, J. S., Wu, W.-C. V., \& Marek, M. W. (2016). Using the flipped classroom to enhance EFL learning. Computer Assisted Language Learning, 30(1-2), 1-21.doi:10.1080/09588221.2015.1111910

Cheung, Y. L. \& Jang, H. (2019). Teaching writing to elementary school students: An activity theory perspective. Irish Educational Studies, 38 (4), 451-466, doi:10.1080/03323315.2019.1645720

Ellis, R. (2008). The study of second language acquisition ( $2^{\text {nd }}$ ed.). Oxford: OUP.

Engeström, Y. (1987). Learning by expanding: An activity theoretical approach to developmental research. Helsinki: Orienta-Konsultit.

Engeström, Y. (1999). Activity theory and individual and social transformation. In Y. Engeström, R. Miettinen, \& R. L. Punamäki (Eds.), Perspectives on activity theory(pp. 19-38). Cambridge: Cambridge University Press.

Engeström, Y. (2009). The future of activity theory: A rough draft. In A. Sannino, H. Daniels\& K. D. Gutiérrez (Eds.) Learning and expanding with activity theory (pp. 303-328). Cambridge: Cambridge University Press.

Fidaoui, D., Bahous, R., \& Bacha, N. N. (2010). CALL in Lebanese elementary ESL writing classrooms. Computer Assisted Language Learning, 23(2), 151-168. doi:10.1080/09588221003666248

Goldberg, A., Russell, M., \& Cook, A. (2003). The effect of computers on student writing: A meta-analysis of studies from1992 to 2002. The Journal of Technology, Learning, and Assessment, 2(1), 1-52. Retrieved fromhttps://ejournals.bc.edu/ojs/index.php/jtla/article/download/1661/1503

Gordon, L. (2008). Writing and good language learners. In C. Griffiths (Ed.), Lessons from good language learners (pp. 244-254). Cambridge: Cambridge University Press.

Hayes, J. R. (2006). New directions in writing theory. In C.A. MacArthur, S. Graham, \& J. Fitzgerald (Eds.), Handbook of writing research (pp. 28-40). New York, NY: Guildford.

Hyland, K. (2003). Second language writing. Cambridge: Cambridge University Press.

Irala, E. A., \& Torres, P. L. (2009). The use of the CMC tool AMANDA for the teaching of English. In R. C. V. Marriott \& P. L. Torres (Eds.), Handbook of research on e-learning methodologies for language acquisition (pp. 307-321). New York: Information Science Reference. doi:10.4018/978-1-59904-994-6

Jacobs, H. L., Zinkgraf, S. A., Wormuth, D. R., Hartfiel, V. F., \& Hughey, J. B. (1981).Testing ESL composition: A practical approach. Rowley, MA: Newbury House.

Jafarian, K., Soori, A., \& Kafipour, R. (2012). The effect of computer assisted language learning (CALL) on EFL high school students' writing achievement. European Journalof Social Sciences, 27(2), 138-148.

Kuutti, K. (1996). Activity theory as a potential framework for human-computer interaction research. In B. Nardi (Ed.), Context and consciousness: Activity theory and human- computer interaction (pp. 17-44). Cambridge, MA: MIT Press. 
Lantolf, J. P., \& Appel, G. (1994). Theoretical framework: An introduction to Vygotskian perspectives on second language research. In J. P. Lantolf \& G. Appel (Eds.), Vygotskian approaches to second language research (pp. 1-32). Norwood, New Jersey: Ablex.

Leffa, V. J. (2009). CALL as action. In R. C. V. Marriott \& P. L. Torres (Eds.), Handbook of research on e-learning methodologies for language acquisition (pp. 39-52). New York: Information Science Reference. doi:10.4018/978-1-59904-994-6

Lei, X. (2008). Exploring a sociocultural approach to writing strategy research: Mediated actions in writing activities. Journal of Second Language Writing, 17(4), 217-236.doi:10.1016/j.jslw.2008.04.001

Lyster, R. (2007). Learning and teaching languages through content: A counter-balanced approach. Amsterdam: John Benjamins.

Mackey, A., \& Gass, S. M. (2005). Second language research: Methodology and design. Mahwah, NewJersey: Lawrence Erlbaum Associates.

Meyers, A. (2006). Composing with confidence: Writing effective paragraphs and essays (7 ${ }^{\text {th }}$ ed.). New York: Pearson Education.

Mosvold, R., \& Bjuland, R. (2011). An activity theory view on learning studies. International Journal of Early Childhood, 43(3), 261-275.doi:10.1007/s13158-011-0048-4

Niami, M. (2011). Impact of teacher feedback and strategic mediation on Iranian EFL learners' writing revision. (Doctoral dissertation, Islamic Azad University, Science and Research Branch).

Naimeh, A. (2017). Computer-assisted language learning: The effect of CALL on Iranian EFL learners writing performance. Theoretical \& Applied Science, 48 (04), 57-63.doi:10.15863/tas.2017.04.48.9

Olshtain, E. (2014). Practical tasks for mastering the mechanics of writing and going just beyond. In M. CelceMurcia, D. M. Brinton, \& M. A. Snow (Eds.), Teaching English as a second or foreign language (4 $4^{\text {th }}$ ed., pp. 208-221). Boston, USA: National Geographic Learning.

Oshima, A., \& Hogue, A. (2014). Longman academic writing series 3: Paragraphs to essays(4th ed.). White Palins, NY: Pearson Education.

Portnov-Neeman, Y., \& Barak, M. (2013). Exploring students'perceptions about learning in school: An activity theory based study. Journal of Education and Learning, 2(3), 9-25. doi:10.5539/jel.v2n3p9

Reid, J. (2001). Writing. In R. Carter \& D. Nunan (Eds.), The Cambridge guide to teaching English to speakers of other languages (pp. 28-33). Cambridge: Cambridge University Press.

Ruetten, M. K. (2012). Developing composition skills: Academic writing and grammar (3 ${ }^{\text {rd }}$ ed.).Boston: Heinle, Cengage Learning.

Seyyedrezaie, Z. S., Ghonsooly, B., Shahriari, H., \& Fatemi, A. H. (2016). A mixed methods analysis of the effect of google docs environment on EFL learners' writing performance and causal attributions for success and failure. Turkish Online Journal of Distance Education, 17(3), 90-110. doi:10.17718/tojde.34418

Shams-Abadi, B. B., Ahmadi, S. D., \& Mehrdad, A. G. (2015). The effect of Edmodoon EFL learners' writing performance. International Journal of Educational Investigations, 2(2), 88-97. Retrieved from http://www.ijeionline.com/attachments/article/36/IJEIonlineVol2No.215208.pdf

Shang, H. F. (2007). An exploratory study of e-mail application on FL writing performance. Computer Assisted Language Learning, 20(1), 79-96. doi:10.1080/09588220601118479 
Swain, M. (1995). Three functions of output in second language learning. In G. Cook \& B. Seidlhofer (Eds.), Principle and practice in applied linguistics: Studies in honor of H. G. Widdowson (pp. 125-144). Oxford: Oxford University Press.

Thorne, S. L. (2003). Artifacts and cultures-of-use in intercultural communication. Language Learning \& Technology, 7(2), 38-67. Retrieved from http://lt.msu.edu/vol7num2/thorne/

Thorne, S. L. (2004). Cultural historical activity theory and the object of innovation. In O. St. John, K.van Esch, \&E. Schalkwijk (Eds.). New insights into foreign language learning and teaching(pp.51-70).Frankfurt, Germany: Peter Lang Verlag

Villalobos, O. B. (2014). Reflections on the connection between computer assisted language learning and second language acquisition. Innovaciones educativas, 14 (19), 11-19.doi: http://dx.doi.org/10.22458/ie.v14i19.644

Villamil, O. S., \& de Guerrero, M. C. M. (1996). Peer revision in the L2 classroom: Social cognitive activities, mediating strategies, and aspects of social behavior. Journal of Second Language Writing, 5(1), 51-75. doi:10.1016/s1060-3743(96)90015-6

Warschauer, M. (1996). Computer assisted language learning: An introduction. Retrieved from http://www.ict4lt.org/en/warschauer.htm

Warschauer, M. (2005). Sociocultural perspectives on CALL. In J. L. Egbert \& G. M. Petrie(Eds.), CALL research perspectives (pp.41-51). Mahwah, New Jersey: Lawrence Erlbaum Associates.

Warschauer, M. (2010). Invited commentary: New tools for teaching writing. Language Learning \& Technology, 14(1), 3-8. Retrieved fromhttp://lit.msu.edu/voll4num1/commentary.pdf

Weigle, S. C. (2014). Considerations for teaching second language writing. In M. Celce Murcia, D. M. Brinton, \& M. A. Snow (Eds.), Teaching English as a second or foreign language (4 ${ }^{\text {th }}$ ed.,pp. 222-237). Boston, USA: National Geographic Learning.

Zemach, D. E., \& Rumisek, L. A. (2005). Academic writing: From paragraph to essay. Oxford: Macmillan.

Appendix A. AT-based CALL Questionnaire (Author \& Author, 2018)

Dear Students,

I would like to ask you to help me by answering the following questions concerning your experience in the Advanced Writing Course. This survey is on activity theory. This is not a test, so there is no "right" or "wrong" answer, and you don't even have to write your name on the questionnaire. I am interested in your personal opinion. Please give your answers sincerely because your responses guarantee the success of the investigation. All the responses will be kept confidential. Thank you very much for your help.

\section{Basic Demographic Information:}

Age: ----------

Sex: Male $\bigcirc$ Female $\bigcirc$

\section{Instructions:}

$>$ Please indicate to what extent each statement is true in your case: Not at all (1), not really (2), to some extent (3), quite a lot (4), or very much (5). 
Example: If the statement is not at all true in your case, mark Not at all:

\begin{tabular}{|c|c|c|c|c|c|}
\hline 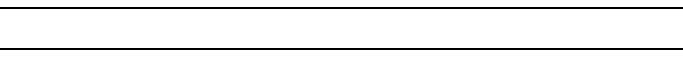 & 1 & 2 & 3 & 4 & 5 \\
\hline Item & $\begin{array}{l}\overline{\bar{\omega}} \\
\bar{\omega} \\
\overline{0} \\
\bar{z}\end{array}$ & 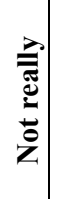 & 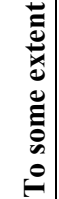 & 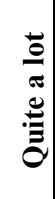 & 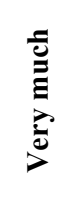 \\
\hline 1. I enjoyed working with the course website. & $X$ & & & & \\
\hline
\end{tabular}

\begin{tabular}{|c|c|c|c|c|c|}
\hline & 1 & 2 & 3 & 4 & 5 \\
\hline Item & $\begin{array}{l}\bar{\sigma} \\
\bar{\sigma} \\
\stackrel{0}{z} \\
\bar{z}\end{array}$ & 㕝 & 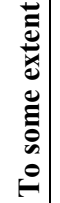 & 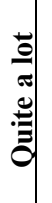 & 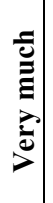 \\
\hline 1. I enjoyed working with the course website. & & & & & \\
\hline 2. I used online sources to write better. & & & & & \\
\hline 3. My classmates' shared materials helped me to write better. & & & & & \\
\hline 4. I used online dictionaries to write better. & & & & & \\
\hline 5. The course book helped me to write better. & & & & & \\
\hline 6. The Grammar Terms available on the website helped me to write better. & & & & & \\
\hline 7. The Writing Tips helped me to write better. & & & & & \\
\hline 8. The Sentence Types and Connecting Words guide available on the website helped me to write better. & & & & & \\
\hline 9. The Connecting Words and Transition Signals guide available on the website helped me to write better. & & & & & \\
\hline 10. The Pre-writing Techniques helped me to write better. & & & & & \\
\hline 11. Grammarly and Paper Rater software helped me to improve my writing. & & & & & \\
\hline 12. I used my teacher's graded samples and feedback to improve my writing. & & & & & \\
\hline 13. It was difficult for me to work with the course website. & & & & & \\
\hline 14. I followed my own way of writing. & & & & & \\
\hline 15. I used materials other than those available or shared on the website to write better. & & & & & \\
\hline 16. The Rating Scale available on the website helped me to write better. & & & & & \\
\hline 17. The Punctuation Rules helped me to use correct punctuation marks in my writing. & & & & & \\
\hline 18. I followed the Page Format rules to write with the correct format. & & & & & \\
\hline 19. The Correction Symbols guide helped me to edit my writing. & & & & & \\
\hline 20. The Writer's Self-Check questionnaires helped me to check and edit my writing. & & & & & \\
\hline 21. It was difficult for me to meet the deadline of the assignments. & & & & & \\
\hline 22. I avoided plagiarism. & & & & & \\
\hline 23. It was difficult for me to email my writing every week. & & & & & \\
\hline 24. My teacher helped me to write better. & & & & & \\
\hline 25. Other university instructors at my university helped me to write better. & & & & & \\
\hline 26. My classmates helped me to write better. & & & & & \\
\hline 27. Other students in my educational environment helped me to write better. & & & & & \\
\hline 28. My friends helped me to write better. & & & & & \\
\hline 29. My family members helped me to write better. & & & & & \\
\hline 30. Other people outside of the university helped me to write better. & & & & & \\
\hline 31. Dividing responsibilities among class members helped me to write better. & & & & & \\
\hline
\end{tabular}




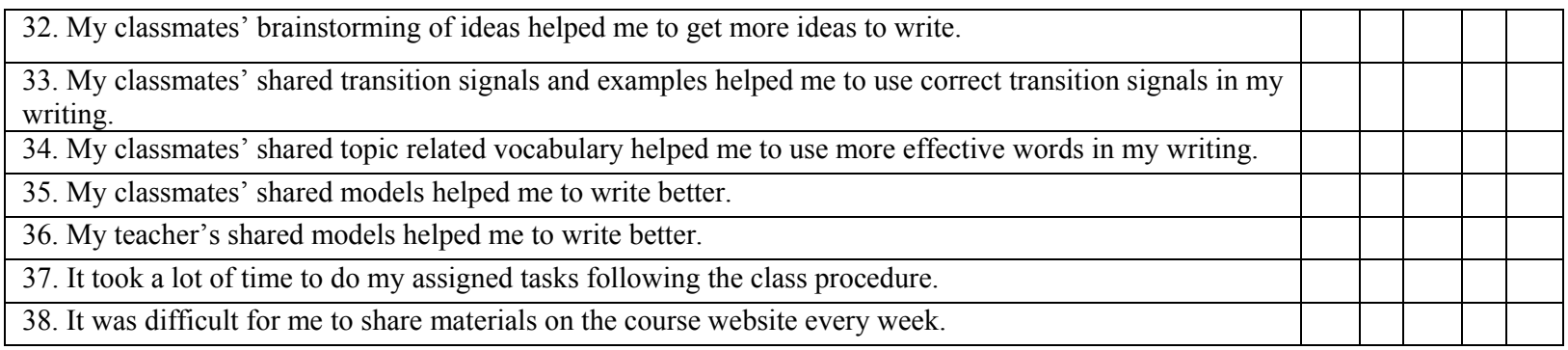

Appendix B. Open-ended Questionnaire

Instructions: Based on your experience in the Advanced Writing Course, please answer the following questions. You can answer the questions in Persian if you like. This is not a test, so there is no right or wrong answer. Your responses help us to improve the course. All of your responses will be kept confidential. Thank you very much for your help.

1. I improved/did not improve my writing during this course because

2. I am satisfied/not satisfied with the progress I have made in my writing following the class procedure because--------

3. I like/dislike to take another writing course following the same procedure because-----

4. What aspects of your writing do you think you have improved/not improved during this course? Put a check mark next to your options.
a. Content: improved/not improved
b. Organization: improved/not improved
c. Proper use of vocabulary: improved/not improved
d. Proper use of grammar: improved/not improved
e. Proper use of mechanics: improved/not improved

5. What were the main strengths and weaknesses of the method used in this course? 